\title{
RANCANGAN USULAN PERBAIKAN UNTUK MEMINIMASI WAITING TIME PADA PROSES PRODUKSI RUBBER STEP ASPIRA BELAKANG DENGAN PENDEKATAN LEAN MANUFACTURING (STUDI KASUS: PT AGRONESIA DIVISI INDUSTRI TEKNIK KARET)
}

\author{
${ }^{1}$ Qolli Kusuma, ${ }^{2}$ Pratya Poeri Suryadhini, ${ }^{3}$ Mira Rahayu \\ 1,2,3Program Studi Teknik Industri, Fakultas Rekayasa Industri, Telkom University \\ 19olykusuma@gmail.com, ${ }^{2}$ pratya@telkomuniversity.ac.id, ${ }^{3}$ mira.rahayu82@gmail.com
}

\begin{abstract}
Abstrak-PT Agronesia (Divisi Industri Teknik Karet) merupakan perusahaan manufaktur industri pengolahan yang memproduksi berbagai jenis produk karet teknik untuk keperluan industri, salah satunya adalah rubber step. Penelitian ini difokuskan pada rubber step Aspira Belakang yang memiliki gap ketidaktercapaian produksi tertinggi. Pada proses produksi rubber step Aspira Belakang ditemukan waktu menunggu yang mempengaruhi tingkat pencapaian target produksi. Tahap awal dalam penelitian ini adalah dengan mengumpulkan data primer yang diolah untuk menggambarkan value stream mapping (VSM) dan process activity mapping (PAM) current state sehingga diketahui lead time dari proses produksi rubber step Aspira Belakang sebesar 5915.07 detik dengan waktu aktivitas value added sebesar 1131.47 detik atau $19.13 \%$ dari lead time. Tahap berikutnya adalah mengidentifikasi penyebab akar masalah waiting time menggunakan peta pekerja-mesin, fishbone diagram dan 5 why. Tahap selanjutnya adalah melakukan analisis 5W1H untuk memaparkan detail masalah dan menentukan rancangan usulan perbaikan menggunakan metode lean manufacturing seperti Quick Changeover dan Display. Rancangan usulan perbaikan berupa perancangan alat potong, pembagian lot pengerjaan compound, pengadaan instruksi kerja, perancangan display, pembuatan batch/stock siap cetak, dan perancangan rak penyimpanan khusus sebagai upaya dalam meminimasi waiting time pada proses produksi rubber step Aspira Belakang. Berdasarkan rancangan usulan yang diberikan didapatkan lead time sebesar 3142.10 detik dengan waktu aktivitas value added sebesar 1131.47 detik atau $36.01 \%$ dari lead time.
\end{abstract}

Kata kunci: Lean Manufacturing, Quick Changeover, Waste Waiting

\section{PENDAHULUAN}

Lean merupakan suatu metode yang sudah tak asing bagi praktisi industri di seluruh dunia. Lean berfungsi dalam meminimasi penggunaan sumber daya dari aktivitas perusahaan melalui upaya perbaikan dan peningkatan terus-menerus yang berfokus pada eliminasi aktivitas yang tidak memberikan nilai tambah kepada pelanggan (customer), sehingga penerapan lean diperlukan untuk setiap perusahaan manufaktur [1]. Namun, dalam kenyataannya terdapat beberapa perusahaan yang belum menerapkan metode ini sebagai upaya dalam membuat proses produksi menjadi efisien.

PT Agronesia (Divisi Industri Teknik Karet) adalah perusahaan manufaktur yang bergerak pada produksi karet teknik, salah satunya adalah rubber step. Terdapat beberapa jenis rubber step yang diproduksi oleh PT Agronesia (Divisi Industri Teknik Karet) yaitu rubber step Yamaha belakang(YB), rubber step Yamaha depan(YD), rubber step Aspira belakang (AB), rubber step Aspira depan (AD), dan rubber step Grand $(G)$. Berikut jumlah permintaan pasar (demand) dan kapasitas produksi rubber step di PT Agronesia (Divisi Industri Teknik Karet) berdasarkan data historis perusahaan pada bulan Agustus 2014 hingga Agustus 2015 yang ditampilkan pada Gambar 1.

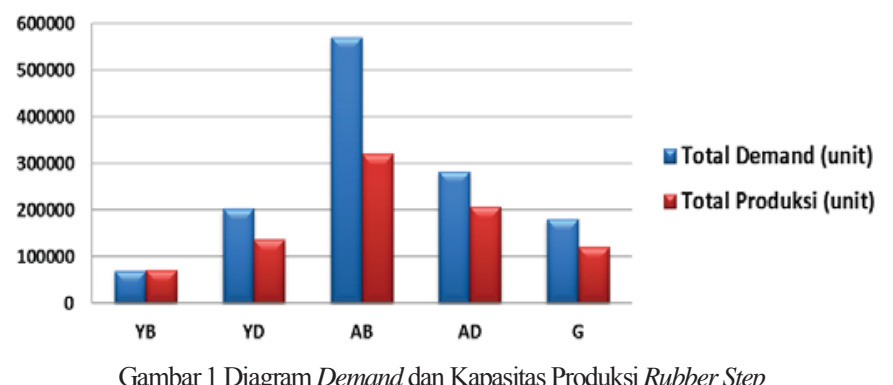

Berdasarkan Gambar 1 diketahui bahwa rubber step Aspira Belakang memiliki gap ketidaktercapaian produksi tertinggi, yaitu sebesar 43.76\% sehingga rubber step Aspira Belakang ditetapkan menjadi fokus penelitian. Dalam pelaksanaan proses produksinya, ditemukan beberapa pemborosan (waste) yang ditunjukkan pada Gambar 2. 


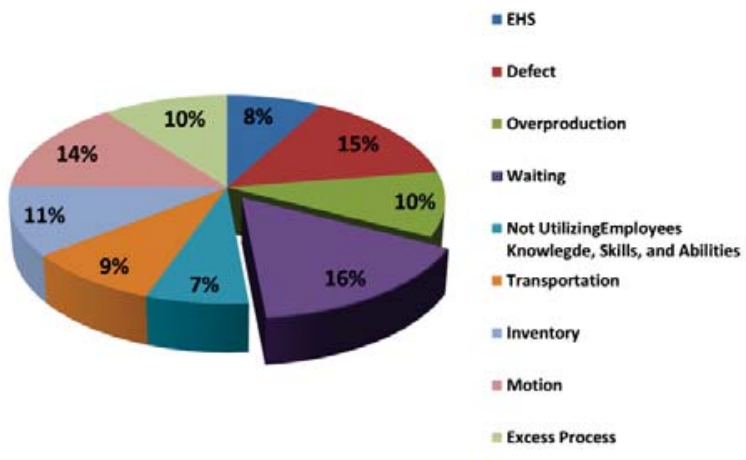

Gambar 2 Waste yang terjadi pada proses produksi rubber step $\mathrm{AB}$

Waste yang paling banyak terjadi pada proses produksi adalah waste waiting sehingga dibutuhkan suatu rancangan perbaikan sebagai upaya minimasi waste waiting yang terjadi pada proses produksi rubber step Aspira belakang untuk mengurangi gap antara kapasitas produksi perusahaan dengan permintaan pasar (demand) dengan pendekatan lean manufacturing.

Terdapat beberapa penelitian terdahulu yang menggunakan pendekatan lean manufacturing sebagai upaya minimasi waste waiting. Tahap awal penelitian dilakukan dengan pembuatan current state mapping dan process activity mapping sehingga didapatkan lead time sebesar 109590,27 detik dengan value added activity sebesar 96892,91 detik atau 88,41\% dari lead time. Akar penyebab permasalahan yang menyebabkan waste waiting adalah tidak adanya pengingat waktu ketika material sudah kering, tidak tersedianya sumber listrik cadangan, dan adanya ketidakseimbangan beban kerja antar workstation, sehingga didapatkan rancangan usulan perbaikan berupa pemasangan timer pada rak dan meja pengeringan, penyediaan genset, dan penyeimbangan lini. Berdasarkan rancangan perbaikan yang diusulkan, didapatkan lead time sebesar 102331,78 detik dengan value added activity sebesar 96892,94 detik atau meningkat menjadi $94,68 \%$ dari lead time [2].

\section{METODE PENELITIAN}

Tahapan perancangan perbaikan proses produksi rubber step Aspira Belakang guna meminimalkan waste yang terjadi ditunjukkan pada Gambar 3. Tahap awal penelitian dimulai dengan melakukan pengamatan kondisi awal proses produksi dan beberapa data yang berhubungan dengan pemborosan yaitu data mesin, alat dan operator yang dibutuhkan. Selanjutnya tahap pembuatan current state design dengan menggunakan Value Stream Mapping (VSM) dan Process Activity Mapping (PAM) untuk mengidentifikasi waste yang terjadi. Langkah berikutnya adalah pencarian faktor penyebab dari waste waiting menggunakan peta pekerja-mesin, fishbone diagram, dan 5 why. Berdasarkan hasil identifikasi akar penyebab permasalahan, kemudian dilakukan rancangan perbaikan untuk meminimasi waiting time pada proses produksi rubber step Aspira Belakang dengan menggunakan tools 5W1H, display, dan Quick Changeover serta hasilnya dianalisis dengan future state design yaitu Value Stream Mapping (VSM) serta Process Activity Mapping (PAM).

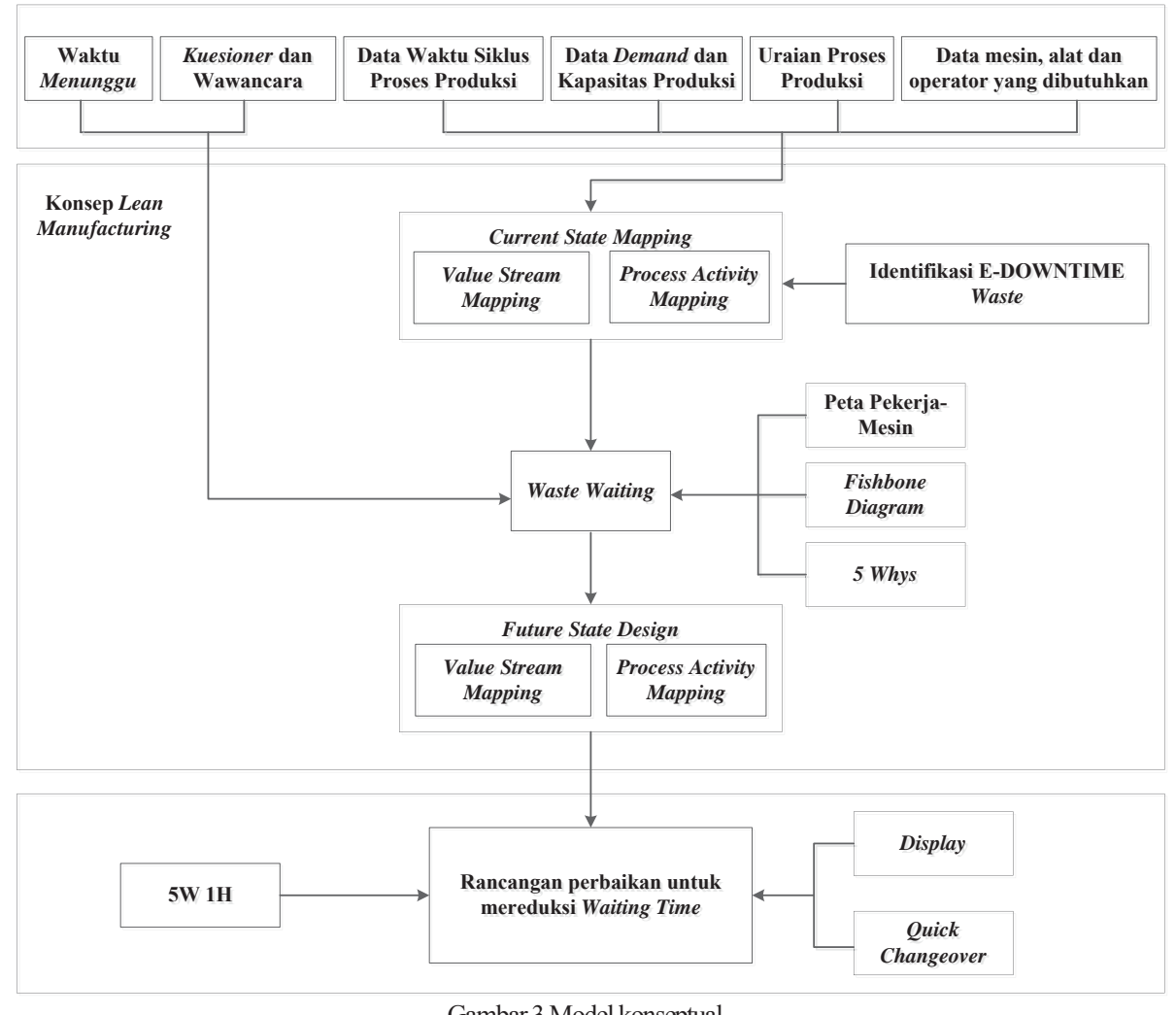

III. HASIL DAN PEMBAHASAN 
Pengamatan dan pengambilan data dilakukan dengan mengambil sampel menggunakan stopwatch serta dilakukan uji kenormalan, keseragaman, dan kecukupan data. Tingkat kepercayaan yang dipilih adalah 95\% karena dalam proses pengamatan waktu terdapat beberapa data waktu yang dibebankan kepada operator. Seluruh sampel yang telah melalui uji kenormalan, keseragaman, dan kecukupan data lalu dilanjutkan dengan perhitungan waktu baku yaitu perhitungan waktu siklus yang dikalikan dengan nilai penyesuaian sehingga menghasilkan waktu normal, kemudian ditambahkan dengan faktor kelonggaran sehingga akan menghasilkan waktu baku[3]. Nilai penyesuaian untuk setiap aktivitas didapatkan dari penyesuaian menurut Westinghouse.

\section{A. Current State Mapping}

Pengumpulan dan pengolahan data dilakukan sebagai proses pemetaan aliran nilai current state dengan menggunakan Value Stream Mapping (VSM) dan Process Activity Mapping (PAM).

\section{Value Stream Mapping (VSM)}

Pemaparan value stream mapping pada Gambar 4 menunjukkan bahwa lead time untuk proses produksi rubber step Aspira Belakang sebesar 5915.07 detik atau 98.58 menit dengan aktivitas bernilai tambah (value added time) sebesar 1131.47 detik atau 18.86 menit.

\section{Process Activity Mapping (PAM)}

Penggambaran process activity mapping (PAM) bertujuan untuk mengetahui aliran proses yang terjadi pada produksi rubber step Aspira Belakang. Berdasarkan penggambaran tersebut, didapatkan nilai aliran proses operasi sebesar $16 \%$, aliran proses transportasi $5 \%$, aliran proses operasi \& inspeksi $5 \%$, dan aliran proses penundaan $75 \%$. Process Activity Mapping juga memaparkan aktivitas atau tahapan proses produksi beserta kategorinya (value added, necessary non value added, dan non value added) yang diperlihatkan pada lampiran A.

B. Identifikasi Penyebab Waste Waiting

Terdapat beberapa kegiatan menunggu di sepanjang proses produksi yang merupakan aktivitas tidak bernilai tambah yang didapatkan dari current state mapping, sehingga diperlukan identifikasi penyebab kegiatan menunggu tersebut dengan peta pekerja-mesin, fishbone diagram dan 5 why.

\section{Peta Pekerja-Mesin}

Total waktu menganggur pada proses produksi rubber step Aspira Belakang adalah sebesar 77.58\%. Waktu menganggur terbesar terdapat pada mesin pemotongan 2 yaitu sebesar 1125.37 detik atau 99,46\% dari waktu total produksi keseluruhan. Waktu menganggur terbesar selanjutnya terdapat pada mesin pemotongan 1 yaitu sebesar 1108.68 detik atau 97,99\% dari waktu total produksi keseluruhan.

\section{Fishbone Diagram}

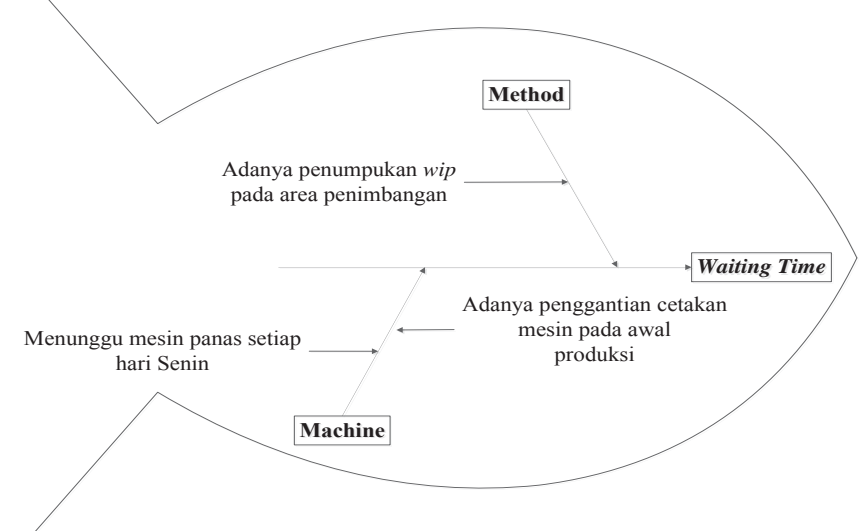

Gambar 5 Fishbone diagram
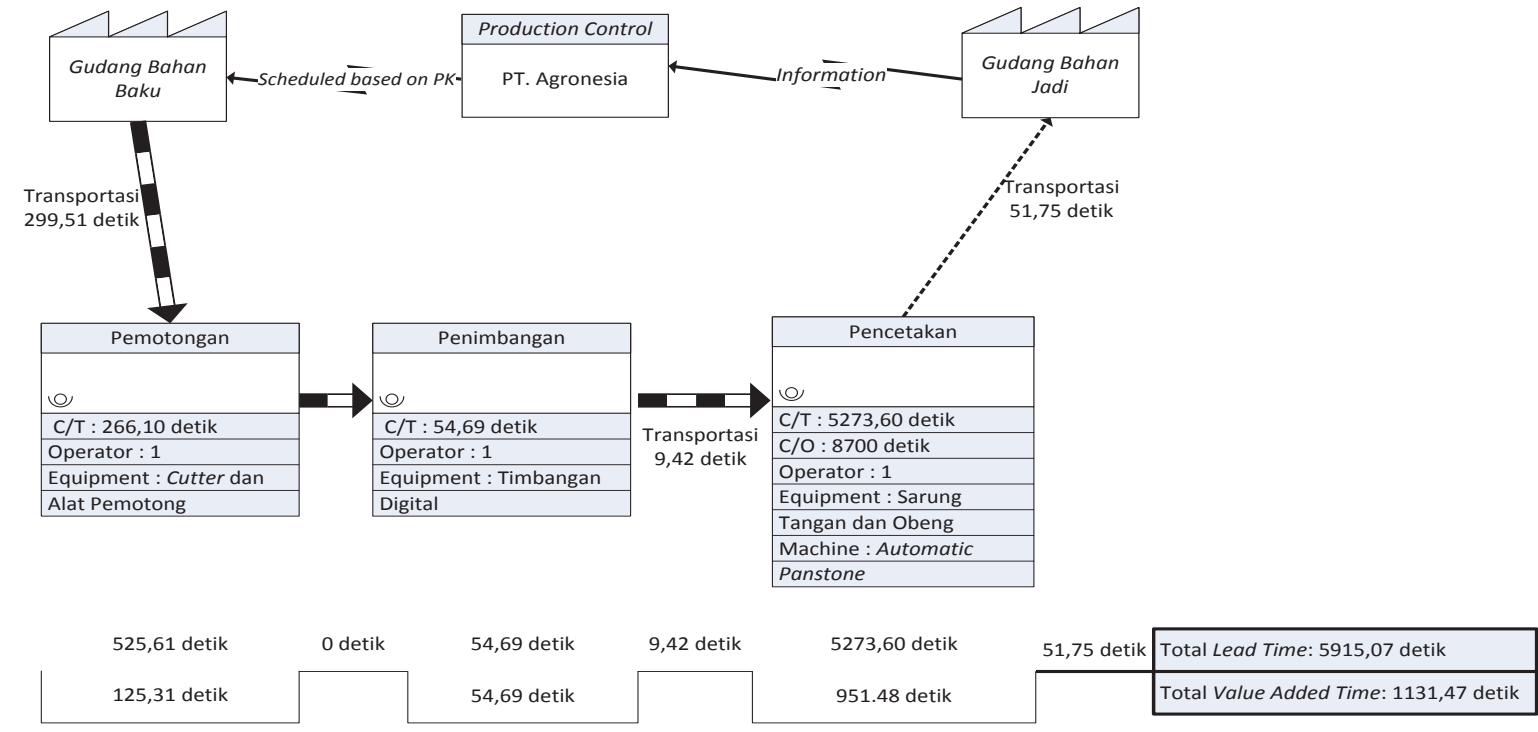

Gambar 4 Value Stream Mapping

Berdasarkan Gambar 5, terdapat dua faktor utama yang step Aspira Belakang di PT Agronesia (Divisi Industri Teknik Karet), menyebabkan terjadinya waiting time pada proses produksi rubber yaitu sebagai berikut. 
a. Method

Kegiatan menunggu terjadi karena adanya faktor metode (Method) yang bersangkutan dengan proses produksi, yaitu adanya penumpukan material atau produk setengah jadi (workin-process) pada area penimbangan. Penumpukan produk setengah jadi (work-in-process) tersebut diakibatkan hanya tersedianya 1 operator untuk melakukan seluruh proses produksi rubber step Aspira Belakang. Selain itu, penumpukan juga terjadi akibat waktu kerja pada area pemotongan lebih kecil dari waktu kerja pada area penimbangan. Penumpukan tersebut menyebabkan adanya tumpukan potongan compound di area penimbangan dan mengurangi ruang gerak bagi operator.

b. Machine

Kegiatan menunggu juga terjadi karena adanya faktor mesin (Machine) yaitu menunggu penggantian cetakan mesin selama 8700 detik (145 menit). Proses menunggu penggantian cetakan mesin ini setidaknya dilakukan 1 kali dalam setiap awal produksi rubber step (setelah turunnya perintah kerja). Kegiatan menunggu lain yang terjadi karena faktor mesin adalah adanya proses menunggu mesin panas selama 4118.53 detik (68.6 menit). Proses menunggu mesin panas ini setidaknya dilakukan satu kali dalam seminggu yaitu pada awal produksi tiap minggu (hari Senin).

\section{5 Why}

Metode 5 Whys digunakan untuk mencari akar permasalahan pada penyebab dominan waiting time proses produksi rubber step Aspira Belakang yang ditunjukkan pada Tabel I.

\section{Rancangan Usulan Perbaikan}

Usulan perbaikan yang dirancang bertujuan untuk mengatasi atau meminimalkan akar penyebab waste waiting yang didapat dari hasil analisis fishbone diagram dan 5 why.

1. Perancangan Alat Potong untuk Melakukan Dua Proses Pemotongan Sekaligus

Proses pemotongan pada produksi rubber step Aspira Belakang dilakukan dua kali yaitu proses pemotongan compound utuh menjadi 11 bagian berukuran $20 \times 70 \mathrm{~cm}^{2}$ dengan cutter selama 22.79 detik dan proses pemotongan dengan alat potong menjadi 33 bagian yang berukuran $20 \times 20 \mathrm{~cm}^{2}$ selama 6.10 detik.
Masalah yang terjadi adalah terdapat dua fasilitas/alat untuk melakukan proses pemotongan yaitu cutter dan alat potong dikarenakan cutter tidak dapat menghasilkan hasil potongan yang presisi sehingga dibutuhkan alat pemotong untuk memotong compound menjadi bagian terkecil yaitu $20 \times 20 \mathrm{~cm}^{2}$.

Rancangan usulan alat potong pada Gambar 6 merupakan alat potong yang dapat melakukan dua proses pemotongan compound sekaligus sehingga dapat digabungkan menjadi 1 proses pemotongan yang bertujuan untuk meminimasi lead time akibat perpindahan fasilitas/alat dan compound serta meningkatkan produktivitas alat pada proses produksi rubber step Aspira Belakang. Selain itu, alat pemotong tersebut dapat memudahkan operator dalam melakukan proses pemotongan sehingga hasil potongan lebih presisi dan rapi. Berdasarkan kegunaan alat potong, maka aktivitas non value added berjalan mengambil cutter dapat dihilangkan.

2. Pembagian Lot Pengerjaan Compound pada Area Pemotongan dan Penimbangan

Komponen utama yang dibutuhkan dalam proses produksi rubber step Aspira Belakang adalah compound yang berbentuk lembaran 230x70x0.5 $\mathrm{cm}^{3}$. Proses pertama dalam produksi rubber step Aspira Belakang adalah pembukaan plastik compound dan penumpukan sebanyak lima tumpukan, kemudian dilanjutkan proses pemotongan compound menjadi 11 bagian dengan cutter. Proses berikutnya adalah pemotongan kembali dengan alat potong menjadi 33 bagian yang berukuran $20 \times 20 \mathrm{~cm}^{2}$. Setelah compound menjadi 33 bagian dengan bentuk persegi berukuran 20x20 cm 2 , kemudian compound ditimbang sebesar \pm 2700 gram dan siap untuk dicetak. Masalah yang terjadi adalah mesin pencetakan memiliki batas maksimal pengerjaan compound yaitu mesin Automatic Panstone hanya dapat mengerjakan satu bagian compound dalam waktu 420 detik sehingga mengakibatkan penumpukan compound pada area penimbangan serta waktu menganggur bagi operator selama 420 detik/compound atau 13860 detik/batch. Perancangan pembagian pengerjaan compound pada area pemotongan dan penimbangan untuk menggantikan waktu menunggu proses pencetakan selama 420 detik dibuat dengan pertimbangan jumlah operator dan penumpukan yang terjadi pada area penimbangan.

Tabel I

HASIL 5 WHY

\begin{tabular}{|c|c|c|c|}
\hline No. & Subcause & Akar Penyebab Masalah & Usulan Perbaikan \\
\hline 1 & \multirow{4}{*}{$\begin{array}{l}\text { Adanya penumpukan produk } \\
\text { setengah jadi (work-in- } \\
\text { process) pada area } \\
\text { penimbangan }\end{array}$} & $\begin{array}{l}\text { Mesin pemotongan memiliki angka } \\
\text { produktivitas kecil }\end{array}$ & $\begin{array}{c}\text { Perancangan alat potong untuk melakukan } 2 \text { proses } \\
\text { pemotongan sekaligus }\end{array}$ \\
\hline 2 & & $\begin{array}{l}\text { Mesin pencetakan memilki batas maksimal } \\
\text { pengerjaan compound }\end{array}$ & $\begin{array}{c}\text { Pembagian lot pengerjaan compound pada area pemotongan } \& \\
\text { penimbangan }\end{array}$ \\
\hline 3 & & $\begin{array}{c}\text { Tidak adanya standarisasi instruksi kerja bagi } \\
\text { operator }\end{array}$ & $\begin{array}{c}\text { Pengadaan instruksi kerja bagi operator terkait proses produksi } \\
\text { rubber step Aspira Belakang }\end{array}$ \\
\hline 4 & & $\begin{array}{l}\text { Tidak adanya pengingat terkait proses } \\
\text { produksi untuk operator }\end{array}$ & $\begin{array}{c}\text { Perancangan display sebagai pengingat operator terkait proses } \\
\text { produksi rubber step Aspira Belakang }\end{array}$ \\
\hline 5 & $\begin{array}{l}\text { Menunggu mesin panas pada } \\
\text { hari Senin }\end{array}$ & $\begin{array}{l}\text { Distribusi compound dari gudang bahan baku } \\
\text { hanya dilakukan saat compound di area } \\
\text { produksi telah menipis }\end{array}$ & $\begin{array}{l}\text { Pembuatan batch/stock siap cetak untuk shift berikutnya } \\
\text { (khusus hari Senin) }\end{array}$ \\
\hline 6 & $\begin{array}{l}\text { Menunggu pergantian cetakan } \\
\text { mesin pada awal produksi }\end{array}$ & Cetakan mesin yang disimpan banyak & $\begin{array}{c}\text { Perancangan rak penyimpanan khusus cetakan rubber step yang } \\
\text { paling banyak diproduksi }\end{array}$ \\
\hline
\end{tabular}


3. Pembagian Lot Pengerjaan Compound pada Area Pemotongan Setelah dilakukan pembagian lot compound dengan metode gannt chart didapatkan bahwa total waktu proses produksi sebesar 27975.22 detik atau menghemat waktu sebesar 2918.87 detik dari proses produksi sebelumnya yang memiliki waktu proses produksi sebesar 30894.10 detik. Hasil pembagian lot pengerjaan compound tersebut dapat dilihat pada lampiran B.

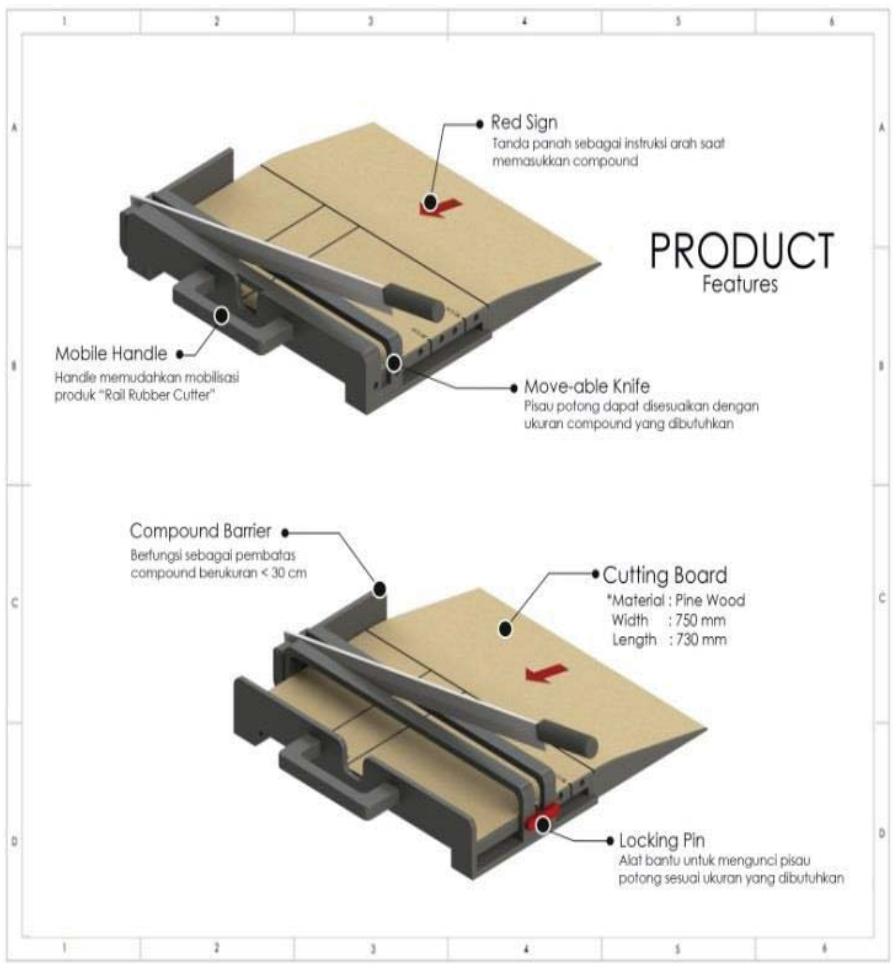

Gambar 6 Rancangan Usulan Alat Potong

4. Pengadaan Instruksi Kerja bagi Operator Terkait Proses Produksi Rubber Step Aspira Belakang

PT Agronesia (Divisi Industri Teknik Karet) menetapkan dua shift per hari sebagai waktu kerja seluruh operator produksinya termasuk operator produksi rubber step Aspira Belakang. Operator produksi rubber step Aspira Belakang yang berbeda setiap shiftnya mengakibatkan urutan proses produksi pun terkadang berbeda. Masalah yang terjadi adalah tidak adanya standarisasi instruksi kerja bagi operator sehingga operator bebas menentukan urutan proses produksi. Instruksi kerja adalah petunjuk instruktif yang menjelaskan tahapan-tahapan kerja secara terperinci. Instruksi kerja yang telah terstandarisasi bertujuan agar kegiatan proses produksi dapat dilakukan secara konsisten untuk setiap operator yang bertugas [4]. Instruksi kerja ini berkaitan dengan rancangan usulan sebelumnya yaitu pembagian pengerjaan compound pada area pemotongan dan penimbangan sehingga dalam penerapannya dapat berjalan dengan lancar dan merata untuk setiap operator. Instruksi kerja akan dilapisi plastik dan ditempel di area pemotongan atau area penimbangan. Lapisan plastik akan membuat instruksi kerja bebas dari kotoran maupun uap dari saluran air yang terletak di bawah dinding area pemotongan dan area penimbangan.

5. Perancangan Display sebagai Pengingat Operator
Pengadaan visual control terkait proses produksi rubber step Aspira Belakang dilakukan untuk menghindari penumpukan produk setengah jadi (work-in-process) pada area penimbangan sehingga lead time yang dihasilkan akan semakin singkat serta agar setiap operator memahami urutan proses produksi rubber step Aspira Belakang yang efisien. Visual control yang dibuat berupa display. Display adalah bagian dari lingkungan yang memberi informasi kepada pekerjanya agar tugas-tugasnya menjadi lancar [5].

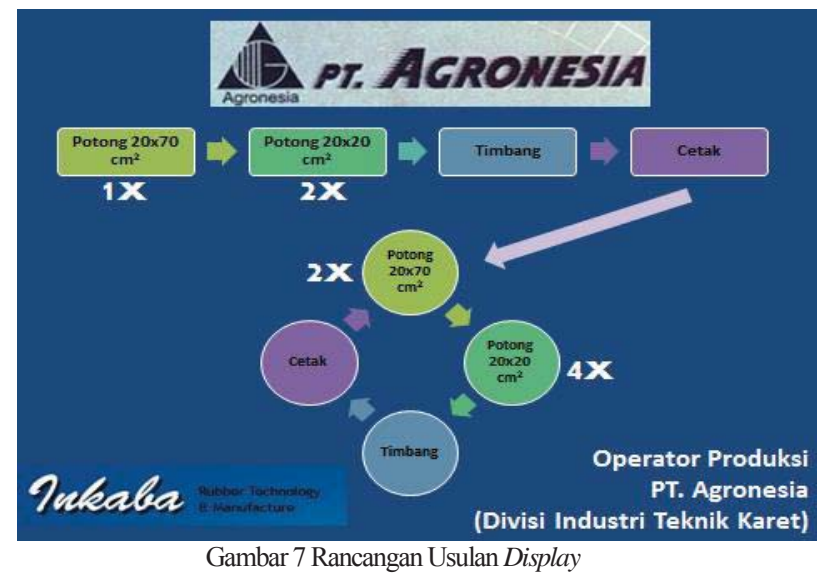

Gambar 7 merupakan rancangan usulan display sebagai pengingat terkait proses produksi rubber step Aspira Belakang. Perancangan display dilakukan dengan bahasa Indonesia yang baik dan benar serta gambar yang menarik dengan tujuan agar display mudah dipahami oleh operator serta operator dapat mengingat urutan proses produksi rubber step Aspira Belakang yang efisien tanpa harus membaca instruksi kerja secara berulangulang. Ukuran display sebesar A3 atau $29.7 \times 42 \mathrm{~cm}^{2}$ agar dapat dilihat dalam jarak 2 meter.

\section{Pengadaan Batch/Stock Siap Cetak untuk Shift II Hari Senin}

PT Agronesia (Divisi Industri Teknik Karet) memiliki jadwal untuk menghidupkan mesin Automatic Panstone selama enam hari berturut-turut yaitu pada hari Senin hingga Sabtu. Hal tersebut dikarenakan mesin Automatic Panstone memiliki daya yang tinggi saat dihidupkan dan waktu setup mesin yang cukup lama yaitu selama 7200 detik sehingga mesin hanya akan dihidupkan pada hari Senin dan dimatikan setelah produksi berakhir pada hari Sabtu. Masalah yang terjadi adalah distribusi compound dari gudang bahan baku hanya dilakukan saat compound di area produksi telah menipis atau 1-2 kali perhari sehingga setelah operator melakukan proses pemotongan dan penimbangan, operator harus menunggu selama 4118.52 detik untuk memulai proses pencetakan dikarenakan mesin Automatic Panstone harus mengalami proses pemanasan selama 7200 detik sedangkan waktu kerja operator per shift adalah 22500 detik untuk melakukan proses produksi rubber step Aspira Belakang. Perancangan pengadaan compound siap cetak untuk shift II hari Senin dilakukan untuk mengurangi waktu menunggu mesin panas, sehingga distribusi compound dari gudang bahan baku hanya dilakukan 1 kali yaitu pada shift I dan operator hanya mengerjakan proses pencetakan pada shift II. Berdasarkan 
rancangan usulan ini, maka dapat meminimalkan kegiatan necessary nonvalue added menunggu mesin panas sebesar 2724.33 detik. Output produk jadi yang dihasilkan oleh aktivitas proses produksi pada hari Senin dengan pengadaan compound siap cetak untuk shift II juga meningkat dari 1092 produk menjadi 1188 produk, sedangkan inventory work-in-process siap cetak berkurang dari 576 produk atau 24 bagian compound siap cetak menjadi 528 produk atau 22 bagian compound siap cetak.

7. Pembuatan Rak Penyimpanan Khusus Cetakan Rubber Step yang Paling Banyak Diproduksi

PT Agronesia (Divisi Industri Teknik Karet) bagian mass production memproduksi berbagai jenis rubber step yang dapat dikerjakan dalam satu mesin, yaitu mesin Automatic Panstone, sehingga setiap awal produksi rubber step harus dilakukan penggantian cetakan terlebih dahulu. Cetakan mesin berbentuk persegi panjang dengan ukuran $51 \times 57.375 \mathrm{~cm}$ dan berat sebesar $200 \mathrm{~kg}$, sedangkan tempat penyimpanan mesin berada di depan pintu masuk area mass production atau berjarak $895 \mathrm{~cm}$ dari mesin Automatic Panstone. Masalah yang terjadi adalah massa cetakan yang berat dan tempat penyimpanan yang jauh menyebabkan penggantian cetakan harus menggunakan alat bantu material handling. Fasilitas alat bantu material handling yang digunakan saat ini untuk membantu penggantian cetakan mesin adalah forklift. Proses produksi rubber step Aspira Belakang tidak akan dimulai jika penggantian cetakan mesin belum selesai dilakukan karena operator yang melakukan proses produksi dan penggantian cetakan mesin adalah satu operator yang sama. Waktu yang diperlukan untuk penggantian cetakan pada awal produksi adalah 8700 detik.
Pada Gambar 8 ditunjukkan rancangan usulan rak penyimpanan cetakan mesin yang memiliki lima slot penyimpanan yang terdiri dari tiga tingkat slot paling bawah yang digunakan sebagai tempat penyimpanan cetakan rubber step yang paling banyak diproduksi yaitu rubber step Aspira Belakang (AB), rubber step Aspira Depan (AD), dan rubber step Yamaha Depan (YD), dan dua slot paling atas digunakan sebagai tempat penyimpanan empat buah handheld vacuum cleaner sebagai rancangan usulan untuk meminimasi waste defect yang dibahas pada penelitian lainnya. Rak penyimpanan usulan memiliki tinggi $172 \mathrm{~cm}$ dengan tinggi masingmasing slot $30 \mathrm{~cm}$ dan lebar $70 \mathrm{~cm}$. Tinggi rak tersebut disesuaikan dengan tinggi rata-rata laki-laki Indonesia usia 20-40 tahun yaitu $169.73 \mathrm{~cm}$ [6].

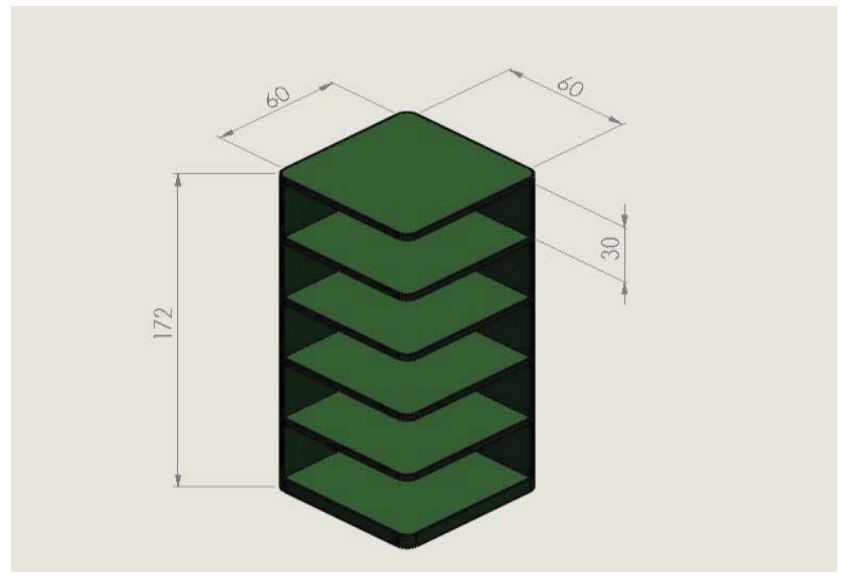

Gambar 8 Rancangan Usulan Rak Penyimpanan

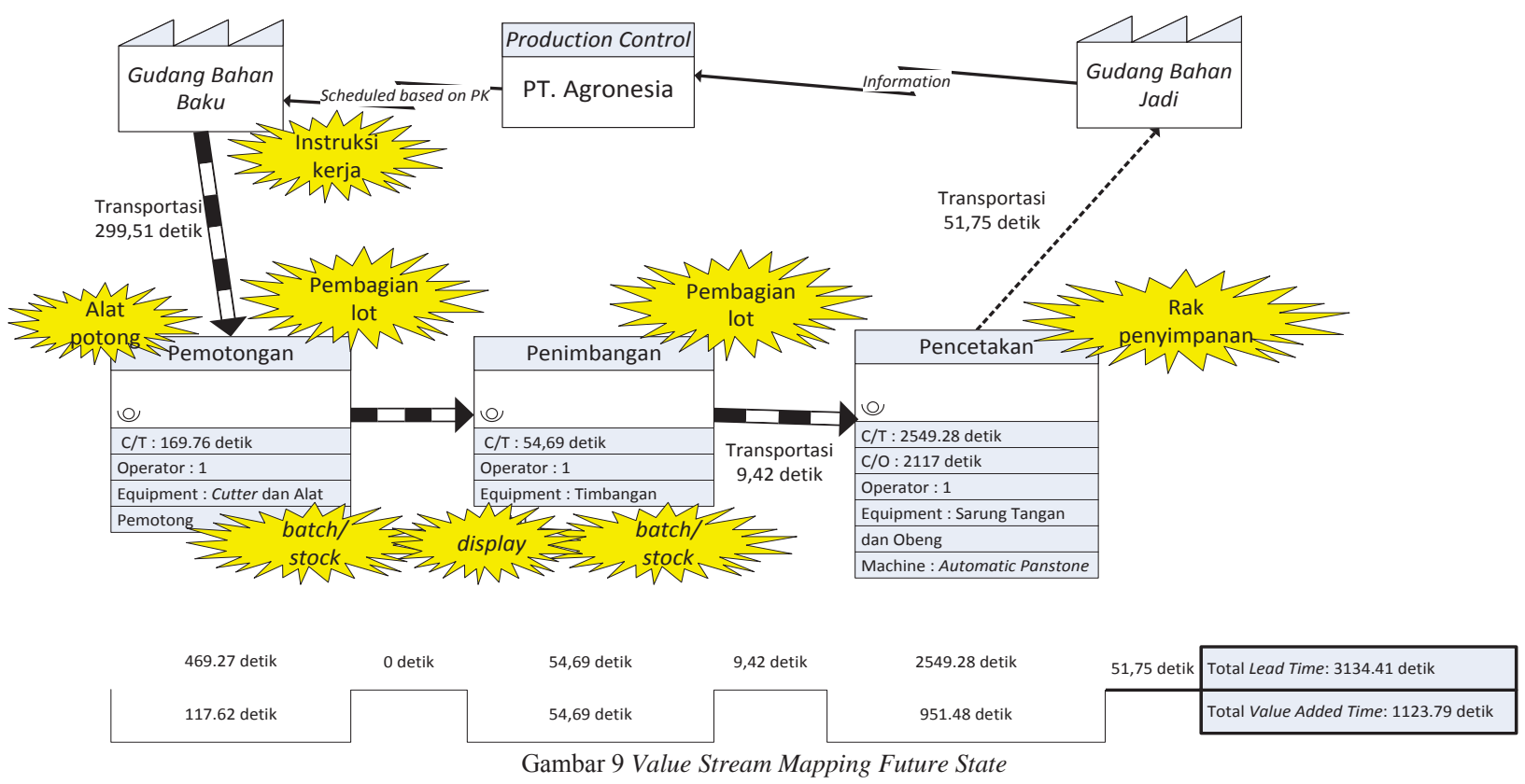




\section{Future State Design}

Future state design memaparkan mengenai pemetaan aliran informasi dan proses setelah diberikannya rancangan usulan perbaikan untuk meminimalkan waiting time yang terjadi [7]. Berdasarkan value stream mapping pada Gambar 9 dan process activity mapping future state didapatkan bahwa lead time proses produksi rubber step Aspira Belakang setelah diberikan rancangan perbaikan adalah 3134.41 detik dengan total aktivitas value added sebesar 1123.79 detik.

\section{KESIMPULAN}

Berdasarkan hasil penelitian didapatkan bahwa terdapapt beberapa akar penyebab waste waiting yang menyebabkan adanya gap ketidaktercapaian produksi pada proses produksi rubber step Aspira Belakang, yaitu penumpukan produk setengah jadi (work-inprocess) pada area penimbangan yang disebabkan oleh kecilnya produktivitas mesin pemotongan, adanya batas maksimal pengerjaan compound pada mesin pencetakan yaitu 1 bagian compound harus dicetak selama 420 detik, tidak adanya standarisasi instruksi kerja bagi operator, dan tidak adanya pengingat terkait proses produksi untuk operator sehingga masing-masing operator memiliki urutan proses yang berbeda-beda. Penyebab waiting time selanjutnya adalah adanya kegiatan menunggu mesin panas pada hari Senin yang diakibatkan karena distribusi compound dari gudang bahan baku hanya dilakukan saat compound di area produksi telah menipis. Penyebab waiting time yang terakhir adalah adanya kegiatan menunggu penggantian cetakan mesin pada awal produksi dikarenakan cetakan mesin yang disimpan banyak sehingga membutuhkan ruang yang luas.

Rancangan usulan perbaikan untuk meminimalkan waiting time yang disebabkan akar penyebab masalah tersebut adalah perancangan alat potong untuk melakukan dua proses pemotongan sekaligus, pembagian lot pengerjaan compound pada area pemotongan dan penimbangan, pengadaan instruksi kerja bagi operator, perancangan display sebagai pengingat untuk operator terkait proses produksi rubber step Aspira Belakang, pengadaan batch/stock siap cetak untuk shift II hari Senin, dan pembuatan rak penyimpanan khusus cetakan rubber step yang paling banyak diproduksi.

Hasil rancangan usulan perbaikan digambarkan menggunakan value stream mapping (VSM) dan process activity mapping (PAM). Berdasarkan value stream mapping dan process activity mapping current state diketahui bahwa lead time produksi sebesar 5915.07 detik dengan total aktivitas value added sebesar 1131.47 detik, sedangkan pada value stream mapping dan process activity mapping future state diketahui bahwa lead time produksi 3134.41 detik atau berkurang sebesar 2780.66 detik dengan total aktivitas value added sebesar 1123.79 detik atau meningkat sebesar 16.72\%.

Mesin atau fasilitas yang digunakan pada proses produksi rubber step Aspira Belakang adalah mesin pemotongan 1 (cutter), mesin pemotongan 2 (alat potong), mesin penimbangan, mesin pencetakan. Rata-rata produktivitas mesin pemotongan adalah $1.275 \%$, sedangkan mesin penimbangan $4.83 \%$, dan mesin pencetakan $37.12 \%$. Setelah diberikan rancangan usulan perbaikan, produktivitas mesin pemotongan menjadi $1.89 \%$ atau meningkat sebesar $0.615 \%$, produktivitas mesin penimbangan menjadi $4.86 \%$ atau meningkat sebesar $0.03 \%$, dan produktivitas mesin pencetakan menjadi $37.37 \%$ atau meningkat sebesar $0.25 \%$.

\section{DAFTAR PUSTAKA}

[1] Gaspersz, V., Total Quality Management untuk Praktisi Bisnis dan Industri, Vinchriso Publication, Bogor, 2011.

[2] Alpharianto, A., Rancangan Usulan Perbaikan Untuk Mengurangi Waiting Time Pada Proses Produksi Gitar Bolt-on di PT Genta Trikarya dengan Pendekatan Lean Manufacturing. Skripsi, Program Studi Teknik Industri, Universitas Telkom, Bandung, 2015.

[3] Suliyanto, Statistika Non Parametrik dalam Aplikasi Penelitian, Penerbit Andi, Yogyakarta, 2014.

[4] Talcha, F., Perancangan Standard Operating Procedure Untuk Memenuhi Requirement Integrasi ISO 9001:2008 Dengan Ohsas 18001:2007 (Klausul 4.4.5, 4.4.6, 4.4.7, 4.5.4, Dan 4.5.5) di CV. GRADIENT Menggunakan Metode Business Process Improvement. Skripsi, Program Studi Teknik Industri, Universitas Telkom, 2015.

[5] Sutalaksana, I. Z., Anggawisastra, R., \& Tjakraatmadja, J. H., Teknik Perancangan Sistem Kerja. Institut Teknologi Bandung, 2006.

[6] http://antropometriindonesia.org/index.php/detail/artikel/4/10/dat a_antropometri, diakses Juni 2016.

[7] Liker, J. K., \& Meier, D., The Toyota Way Fieldbook, Penerbit Erlangga, Jakarta, 2007. 
LAMPIRAN

Lampiran A. Process Activity Mapping

\begin{tabular}{|c|c|c|c|c|c|c|c|c|c|c|c|}
\hline \multirow{2}{*}{ No } & \multirow{2}{*}{ Area } & \multirow{2}{*}{ Aktivitas } & \multirow{2}{*}{ Aliran } & \multirow{2}{*}{$\begin{array}{l}\text { Waktu Proses } \\
\quad \text { (dtk) }\end{array}$} & \multirow{2}{*}{ Operator } & \multicolumn{5}{|c|}{ Aliran } & \multirow{2}{*}{ Keterangan } \\
\hline & & & & & & $\mathbf{O}$ & $\mathbf{T}$ & I & $\mathbf{S}$ & D & \\
\hline 1 & \multirow{3}{*}{ Gudang Bahan Baku } & Mencari Material Handling Equipment & $\mathrm{D}$ & 11.59 & 1 & & & & & & NVA \\
\hline 2 & & Berjalan ke gudang bahan baku & $\mathrm{D}$ & 46.35 & 1 & & & & & & NVA \\
\hline 3 & & Membawa bahan baku ke area pemotongan & $\mathrm{T}$ & 241.57 & 1 & & & & & & NNVA \\
\hline 4 & \multirow{7}{*}{ Pemotongan } & Membuka gulungan compound & $\mathrm{O}$ & 63.57 & 2 & & & & & & VA \\
\hline 5 & & $\begin{array}{l}\text { Membuka plastik pelindung compound dan menumpuk } \\
\text { menjadi } 5 \text { tumpukan }\end{array}$ & $\mathrm{O}$ & 32.85 & 2 & & & & & & VA \\
\hline 6 & & Berjalan mengambil cutter & $\mathrm{D}$ & 48.65 & 1 & & & & & & NVA \\
\hline 7 & & $\begin{array}{c}\text { Memotong lembaran compound dengan usulan alat pemotong } \\
\text { menjadi } 20 \times 70 \mathrm{~cm} 2\end{array}$ & $\mathrm{O}$ & 22.79 & 1 & & & & & & VA \\
\hline 8 & & $\begin{array}{l}\text { Memotong lembaran compound dengan usulan alat pemotong } \\
\text { menjadi } 20 \times 20 \mathrm{~cm} 2\end{array}$ & $\mathrm{o}$ & 6.10 & 1 & & & & & & VA \\
\hline 9 & & Berjalan mengambil alat kebersihan & $\mathrm{D}$ & 31.37 & 1 & & & & & & NVA \\
\hline 10 & & Merapihkan dan membuang sampah plastik & $\mathrm{T}$ & 20.77 & 1 & & & & & & NVA \\
\hline 11 & \multirow{2}{*}{ Penimbangan } & Menimbang hasil pemotongan compound \pm 2700 gram & $\mathrm{O}$ & 54.69 & 1 & & & & & & $\mathrm{VA}$ \\
\hline 12 & & Mengantar compound ke mesin pencetakan & $\mathrm{T}$ & 9.42 & 1 & & & & & & NNVA \\
\hline 13 & \multirow{7}{*}{ Pencetakan } & Menunggu mesin panas & $\mathrm{D}$ & 4118.53 & 1 & & & & & & NNVA \\
\hline 14 & & M enggunakan sarung tangan & $\mathrm{O}$ & 11.87 & 1 & & & & & & NVA \\
\hline 15 & & $\begin{array}{c}\text { Memasukkan compound ke dalam mesin pencetakan } \\
\text { Automatic Panstone }\end{array}$ & $\mathrm{O}$ & 104.21 & 1 & & & & & & VA \\
\hline 16 & & Proses pencetakan & $\mathrm{O}$ & 420 & 1 & & & & & & VA \\
\hline 17 & & Berjalan ke area penimbangan & $\mathrm{D}$ & 7.58 & 1 & & & & & & NVA \\
\hline 18 & & Membersihkan hasil cetakan produk & $\mathrm{O}$ & 85.99 & 1 & & & & & & $\mathrm{VA}$ \\
\hline 19 & & Berjalan mengambil obeng & D & 43.4 & 1 & & & & & & NVA \\
\hline
\end{tabular}




\begin{tabular}{|c|c|c|c|c|c|c|c|c|c|c|c|}
\hline \multirow{2}{*}{ No } & \multirow{2}{*}{ Area } & \multirow{2}{*}{ Aktivitas } & \multirow{2}{*}{ Aliran } & \multirow{2}{*}{$\begin{array}{l}\text { Waktu Proses } \\
\quad \text { (dtk) }\end{array}$} & \multirow{2}{*}{ Operator } & \multicolumn{5}{|c|}{ Aliran } & \multirow{2}{*}{ Keterangan } \\
\hline & & & & & & o & $T$ & I & $\mathbf{S}$ & D & \\
\hline 20 & \multirow{7}{*}{ Pencetakan } & $\begin{array}{c}\text { Mengambil produk jadi rubber step AB dan melakukan } \\
\text { inspeksi produk }\end{array}$ & O\&I & 126.84 & 1 & & & & & & VA \\
\hline 21 & & Merapikan hasil cetakan kembali & $\mathrm{O}$ & 53.37 & 1 & & & & & & $\mathrm{VA}$ \\
\hline 22 & & Menyimpan produk jadi rubber step $\mathrm{AB}$ & $\mathrm{O}$ & 4.44 & 1 & & & & & & $\mathrm{VA}$ \\
\hline \multirow{2}{*}{$\frac{23}{24}$} & & Berjalan mengambil plastik pengepakan & $\mathrm{D}$ & 20.07 & 1 & & & & & & NVA \\
\hline & & Melakukan proses pengepakan dan mengecek hasil inspeksi & O\&I & 156.62 & 1 & & & & & & VA \\
\hline 25 & & Berjalan mengambil alat kebersihan & $\mathrm{D}$ & 54.39 & 1 & & & & & & NVA \\
\hline 26 & & Membersihkan area pencetakan & $\mathrm{O}$ & 66.29 & 1 & & & & & & NVA \\
\hline 27 & \multirow{2}{*}{ Gudang Barang Jadi } & Berjalan mengambil material handling equipment & $\mathrm{D}$ & 31.88 & 1 & & & & & & NVA \\
\hline \multirow[t]{8}{*}{28} & & Mengantarkan produk jadi ke gudang barang jadi & $\mathrm{T}$ & 19.87 & 1 & & & & & & NNVA \\
\hline & \multicolumn{2}{|r|}{ LEAD TIME } & 5915.07 & $\sec$ & & & & & & & \\
\hline & \multicolumn{2}{|c|}{ TOTAL VALUE ADDED TIME } & 1131.47 & $\sec$ & & & & & & & \\
\hline & \multicolumn{2}{|r|}{$\%$ VALUE ADDED } & 19.13 & $\%$ & & & & & & & \\
\hline & \multicolumn{2}{|c|}{ TOTAL NECESSARY NON-VALUE ADDED TIME } & 4389.39 & $\sec$ & & & & & & & \\
\hline & \multicolumn{2}{|c|}{$\%$ NECESSARY-NON VALUE ADDED } & 74.21 & $\%$ & & & & & & & \\
\hline & \multicolumn{2}{|c|}{ TOTAL NON-VALUE ADDED TIME } & 394.21 & $\mathrm{sec}$ & & & & & & & \\
\hline & \multicolumn{2}{|c|}{$\%$ NON VALUE ADDED } & 6.66 & $\%$ & & & & & & & \\
\hline
\end{tabular}


Lampiran B. Gannt Chart Pembagian Lot Compound

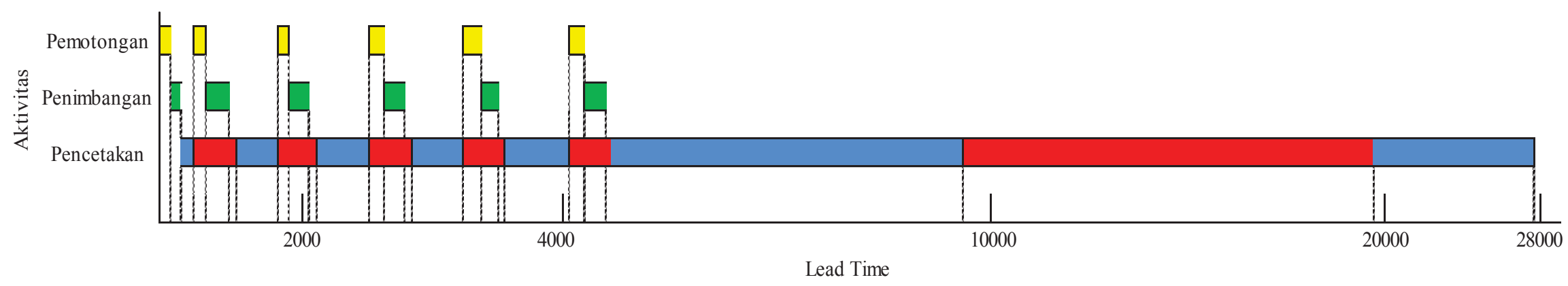

